\title{
Indigenous Knowledge Realized: Understanding the Role of Service Learning at the Intersection of Being a Mentor and a College-Going American Indian
}

\author{
Christine A. Nelson \\ University of New Mexico \\ Natalie R. Youngbull \\ University of Arizona
}

\begin{abstract}
The article explores the experiences of 13 undergraduate American Indian college students who served as mentors through a service-learning course while attending a 4year, predominantly White institution (PWI). This chapter elucidates how serving as a mentor allowed participants to draw on three culturally relevant persistence factors in higher education: relationship, community, and power. Previous research demonstrates that service learning actively involves college students and encourages them to build a connection and a sense of commitment to the community (Lee \& Espino, 2011; Rhoads, 1998). Through a Tribal Critical Race Theory lens, the purpose and function of service learning is deconstructed and redefined to fit the needs of North American Indigenous college students. This article reveals that Indigenous undergraduate students tapped into their own supply of Indigenous knowledge in relating their mentoring experience to building meaningful relationships, to being a positive influence in tribal communities, and to recognizing that service is a cyclical power that positively impacts their collective role in society. The article details how relationship, community, and power from Indigenous perspectives are sources of persistence for American Indian students and how social justice-based, service-learning courses provide safe spaces for students to realize their Indigenous knowledge while attending PWIs.
\end{abstract}

Keywords: American Indian college student; service learning; Indigenous knowledge

\section{Author Note}

Christine A. Nelson, Center for Education Policy Research, University of New Mexico.

Natalie R. Youngbull, Center for the Study of Higher Education, University of Arizona.

Correspondence concerning this article should be addressed to Christine A. Nelson at cnelson22@unm.edu or Natalie R. Youngbull at msrose@email.arizona.edu 


\section{Indigenous Knowledge Realized: Understanding the Role of Service Learning at the Intersection of Being a Mentor and a College-Going American Indian}

\section{American Indian College Students’ Service as Mentors}

As a freshman, everything was new to me especially transitioning to campus and college life. I remember being nervous and shy meeting my mentor for the first time. We quickly found out that we both were what some call "Heinz 57" Natives-representing multiple tribal affiliations! And that kind of broke the ice for us. But it wasn't anything she said in particular that made me feel comfortable-it was how she presented herself. She made me feel important. I felt as though she truly cared about my well-being and was committed to helping me be successful in my academic endeavors... which was surprising to me because we had just met. Her role in my life has grown to encompass mentor, friend, colleague, and most importantly, sister. We've become part of each other's family. Our lives are intertwined and I am truly blessed to have her as a source of leadership, guidance, and inspiration. (Natalie, personal communications, June 20, 2015)

"I would like to introduce Dr. Nelson" stated my dissertation chair as I entered a hallway filled with faces that were beaming with happiness. One excited face was of a student I met during her senior year of high school. Now a senior in college, she relayed to me, "I remember the story you told us of how you were so overwhelmed when you missed the campus tour at Arizona State University that you left and never went back. It's inspiring to see how you went from that scared student to accomplishing your doctorate." Until that moment, I never fully understood the impact of sharing my experiences in higher education. I had just successfully defended my dissertation, but the words provided by the student I mentored, and the feelings that followed those words, will forever remind me of the power of mentorship. (Christine, personal communications, June 20, 2015)

Whether it is serving as a mentor or being a recipient of mentoring, the provided vignettes demonstrate how we have been affected by this form of service in higher education. In a time when national statistics profile the American Indian college student group as not accessing and retaining higher education at the same rates as their peers (see DeVoe, Darling-Churchill, \& Synder, 2008; Ginder \& Kelly-Reid, 2013; Jackson \& Turner, 2004), we offer this paper as a counternarrative to the deficit views of American Indian college students. Throughout this inquiry, we use the term American Indian, Native, tribal and Indigenous interchangeably. This by no means disregards the diversity that exists amongst the numerous tribes of North America. This article begins by presenting the research problem and a short overview of service-learning literature. We continue by introducing the method of inquiry and the role of Tribal Critical Race Theory (TribalCrit) in this study. Through a reflexive, service-learning model, we synthesize three concepts relevant to the mentoring experience for American Indian students: (a) a sense of relationship, (b) a sense of community, and (c) a sense of power. We conclude by positioning the implications of Native students asserting their Indigenous knowledge in higher education. 
Through an Indigenous, strength-based approach, the inquiry questions guiding this project attempt to uncover the experiences of Indigenous college student mentors and their role in a service-learning course. The questions are as follows:

1. How do American Indian college students describe their service-learning experience as mentors?

2. How does mentoring, as an act of social justice and through the lens of Tribal Critical Race Theory (TribalCrit), reveal elements of Indigenous knowledge in the higher education setting?

TribalCrit was the theoretical framework utilized in this project because it was culturally relevant to the specific population under study. Therefore, this exploratory journey particularly seeks to understand ways that serving as a mentor influences three particular realms: relationship, community, and power.

\section{Service Learning to Reveal Indigenous Ways of Knowing}

Previous research has demonstrated that service learning actively involves college students and encourages them to build a connection and a sense of commitment to the community (Lee \& Espino, 2011; Rhoads, 1998). Additionally, service-learning literature supports the notion of how engaging in service promotes social change and student engagement (Lee \& Espino, 2011; Lui, 1999). Despite knowing the implications of service learning, there exists no testimony exploring the experiences of American Indian students who engage in service learning. When conducting a review of the literature we ran multiple queries through the EBSCO, Google Scholar, and ERIC databases using the following keywords in varied combinations: "American Indian student," "Native American student," "Indigenous student," "service-learning," and "mentor." Through EBSCO, seven articles appeared with the keyword combination of "American Indian student" and "Service-Learning." Six of the articles focused on experiences where an outsider was entering Native communities to enhance learning (Chollett, 2014; Dunkel, Shams, \& George, 2011; Harmon-Vukic \& Schanz, 2012; Roche, 2014; Steinman, 2011; Strickland, Logsdon, Hoffman, \& Garrett Hill, 2014). Lee’s (2009) work was the only article to discuss Native student perspectives. However, these perspectives focused more on how students perceived their experiences in a Native American Studies department, not specifically their service-learning experiences.

Our inquiry on this service-learning project contributes directly to a gap in American Indian service learning by qualitatively examining the transformative effect service learning has for Native college students. The lack of Native student experience within service learning is alarming for two reasons. First is how previous service-learning research has been shown to have a transformative impact on civic engagement and awareness (Lee \& Espino, 2011; Lui, 1999; Rhoads, 1998). Second is how a sense of responsibility and community is overwhelmingly germane when it comes to the American Indian student experience (Brayboy, 2004; Shotton, Oosahwe, \& Cintron, 2007). Coupling these two reasons together points to how this study asserts service learning as a viable method to understand how American Indian college students activate their Indigenous knowledge while engaging in the college setting and service learning. 


\section{Framing Our Inquiry}

\section{Tribal Critical Race Theory}

As American Indians represent distinct backgrounds, cultures, and traditions apart from the dominant society, there is need to properly represent this uniqueness in a theoretical perspective. Tribal Critical Race Theory, or TribalCrit, is utilized as the method of inquiry to understand the experiences of American Indian college students serving as mentors. It is imperative to recognize that TribalCrit is a branch of Critical Race Theory (CRT). CRT is a direct response to revealing and altering the inequitable role of race, and other subordinate identifiers such as class and gender, found in society and its institutions. Though CRT is a framework that allows the voices of persons of color to be highlighted and brought to the forefront in research, Brayboy (2005) tackles the insufficiency of CRT to particularly focus on American Indian's special relationship with the U.S. government as both a political and racial group. TribalCrit is based "in the multiple, nuanced, and historically and geographically located epistemologies and ontologies found in Indigenous communities” (Brayboy, 2005, p. 427). Thus, Brayboy (2005) developed TribalCrit to specifically represent the voice of American Indians across fields, but with special emphasis in education. He outlines nine tenets to TribalCrit but only four tenets are focused on for this service-learning study (for a complete description of all tenets see Brayboy, 2005).

Tenet 1: Colonization is endemic to society. When students enroll in mainstream colleges and universities, they are entering institutions that were historically meant to empty their tribal identities (Carney, 1999). This study uses this tenet to understand if and how students, who engage in service learning, describe their experience as a counter narrative to the acculturation function of higher education.

Tenet 2: U.S. policies toward Indigenous peoples are rooted in imperialism, White supremacy, and a desire for material gain. This tenet acknowledges that the purpose and function of higher education serves a non-Indigenous perspective of individual and independent gain. By acknowledging this opposition, this study seeks to understand if and how service learning exposes alternative perspective of higher education such as collectivity and interdependence.

Tenet 3: Indigenous peoples occupy a liminal space that accounts for both the political and racialized natures of our identities. In addition to American Indian students being classified as a racial category, they are also operating in a political arena that is unique from all other racial groups. When American Indian students enter higher education, it is important to consider if and how tribal status intersects with servicelearning experiences.

Tenet 4: The concepts of culture, knowledge, and power take on new meaning when examined through an Indigenous lens. This tenet introduces and validates a new lens for deconstructing how American Indian perspectives operate in a mainstream higher education setting. This tenet pulls together the other three tenets so American Indian students are no longer viewed through a deficit lens. 
Along with culture and power, knowledge is an important factor of education that offers distinct ways of viewing American Indian issues through an Indigenous lens. TribalCrit discards the idea of assimilation in terms of educational institutions and embraces narrative, a cornerstone to Indigenous people, as a tool generating data relevant to scholarly research and theory. Furthermore, it encourages researchers, practitioners, and students to bridge "Indigenous notions of culture, knowledge, and power with western/European conceptions in order to actively engage in survivance, selfdetermination, and tribal autonomy" (Brayboy, 2005, p. 437). TribalCrit aims to uncover the discrepancies between Western values and American Indian values, beliefs, and traditions in societal structures and institutions, particularly educational institutions, with the goal of improving the experiences of American Indian students.

\section{Our Inquiry}

This service-learning inquiry originated from a large-scale study that we both served as graduate research assistants. The original study examined undergraduate students' view of civic duty and responsibility at the culmination of their participation in the servicelearning program. The service-learning course included a specific section for the Native undergraduate students where in different points in time, we served as instructors of that section. Though the methods of data collection in the larger study followed a Western paradigm of data collection, the authors, who are both Indigenous used their positions as data collectors, analyzers, and writers in terms of warrior scholarship (Alfred, 2004). Warrior scholarship works in tandem with TribalCrit by privileging research through an Indigenous lens, where the goal of the inquiry actively serves and promotes the livelihood of Indigenous communities. To accomplish this act, we sought to infuse our working knowledge of Indigenous-based inquiry to understand the essence of service-learning experiences and to be advocates for the students who participated in service learning. Throughout the remainder of this article, we purposely describe the participants as our brothers and sisters because as warrior scholars we have an obligation to the students and the communities they come from. In order to uncover and maintain the essence(s) within this inquiry, it is important to understand that "the meanings that American Indian students ascribe to their experiences are strongly shaped by their cultural constructs" (Shotton et al., 2007, p. 86). We do not claim to be using a decolonized approach to inquiry, but our approach provides the space to practice and hone our warrior approach to Indigenous inquiry.

\section{Our Brothers and Sisters}

Within the larger service-learning study, we identified 13 American Indian college students, between the ages of 18 and 22, who engaged in a conversation with us about their experiences as mentors and their views of civil service. Engaging our warrior scholar techniques, our interaction with the students was always tempered by our obligation to the students as our brothers and sisters. We committed ourselves to protecting our sisters and brothers while understanding the knowledges they used in their service-learning experiences. At the time of the inquiry, three students were seniors, six were juniors, three were sophomores, and one was a freshman. All our brothers and sisters had been in the program for at least one semester and completed 24 hours of service. All students identified as enrolled members from tribal communities within 
Arizona and New Mexico. Ten students grew up rurally on or near the reservation, while three grew up in urban settings, such as in or near large cities. Eleven students were female, and two were male. None of our student mentors had any formal mentoring experience prior to enrolling in the service-learning class.

\section{Mentoring Program: Our Place of Interaction}

Our younger brothers and sisters participated in a 3-credit hour service-learning course where they were instructed on how to build a positive mentoring relationship with middle and high school Indigenous students. They had the opportunity to continue in the program by participating in a 1-credit hour course to further develop skills and understanding as America Indian mentors. The program was rooted in promoting a nearpeer mentoring environment where Indigenous youth would learn from Indigenous mentors about college. Each Indigenous mentor was paired up with one to three American Indian mentees at local middle and high schools where there was a substantial American Indian student population.

\section{Hearing and Processing}

Individual conversations lasted from 45 to 60 minutes. The conversations began with a predetermined protocol, but they unfolded through storytelling methods as our younger brothers and sisters engaged in recounting why they enrolled in the servicelearning course and what personal changes were experienced during and after the process. Their testimonies were enriched while validating the TribalCrit tenet of seeing storytelling as valid sources of knowledge (Brayboy, 2005). The relational approach described by Wilson (2008) as a central component to research with Indigenous populations aided our understanding of the student's lived experiences and also allowed for our brothers and sisters to use their storytelling skills to share experiences and subsequently, gave power to their experiences.

After hearing the testimonies of our brothers and sisters, we reviewed each of the transcribed conversations alone. Then, we came together and shared emergent ideas. Many long discussions and processing led to a deeper understanding of emerging themes that were cross-compared for content. Slowly, student-based knowledges arose that were grounded on the power of the students' voices and experiences. Developing the models allowed us to visualize and describe the interconnectedness of the findings.

\section{Our Brothers' and Sisters’ Knowledge}

Through the lens of TribalCrit and our dedication to acknowledging our Indigenous ways of knowing, a greater awareness of American Indian college students' mentoring experiences emerged. The knowledge demonstrated that a common Indigenous culture served as the basis for establishing the mentoring relationships. In the process, the mentors strengthened not only their sense of self as intricately tied to a larger community, but also their commitment to serving their respective communities and larger society, thus strengthening their commitment to their education.

While TribalCrit justifies the need for American Indian research that is culturally based, Indigenous Knowledge explains the cultural values among our younger brothers and sisters. Service-learning, in the form of near-peer mentoring, serves as an ideal 
pathway for American Indian college students to experience the familiarity of community building and involvement. Existing knowledge has identified a sense of selflessness occurring in college students who participate in service-learning (Lee \& Espino, 2011; Rhoads, 1998, 2000) but for American Indian college students this phenomenon could be linked to more than an individual personality trait or concept.

Prior to European contact, American Indian communities used various social systems to survive. These systems are in practice today, but are marginalized in favor of sustaining the status quo of education as an individualistic and compartmentalized process (Brayboy, Fann, Castagno, \& Solyom, 2012). The specifics of the Indigenous knowledge epistemology vary from tribal community but all include an emphasis on holistic thinking that views all objects as related. Deloria and Wildcat (2001) use three overarching concepts-Power + Place $=$ Personality-to elucidate their take on Indigenous knowledge. In this context, power does not refer to the Western thought of individual power, rather "the living energy that inhabits and/or composes the universe (p. 23). Place is "the relationship of things to each other" (p. 23). Place is not the physical location where the interaction occurs, but the relationship that develops from the interaction. This relationship needs to remain balanced in order to maintain positive living.

The Indigenous concept of power and place strongly contrasts the mainstream scientific method of disaggregation, compartmentalization, and classification. Western ideologies place the human at the top of the pyramid of interaction, while Indigenous ways of knowing position the human at an equal point in the ecological system that is surrounded by all beings and all actions impacting the balance of life. In continuing with Deloria and Wildcat's (2001) concept, personality results when power and place interact. Personality is the everyday occurrences that fills the world, and in regards to Indigenous knowledge, individual actions are never singular or linear, but cyclical (Cajete, 2005). To understand Indigenous knowledge in an educational context, one must recognize that the learning process is never ending.

As a way to synthesize the central components of Indigenous knowledge, we focus on three concepts relevant to the mentoring experience for American Indian students: (a) a sense of relationship, (b) a sense of community, and (c) a sense of power. We want to clearly acknowledge that inherent to Indigenous knowledge is the interrelatedness of all these areas; however, to effectively convey this knowledge to an academic setting, each of these areas are described separately. Figure 1: Indigenized Service-Learning Model (below) visually demonstrates the interconnectedness of the service-learning experience with Indigenous ways of knowing. 


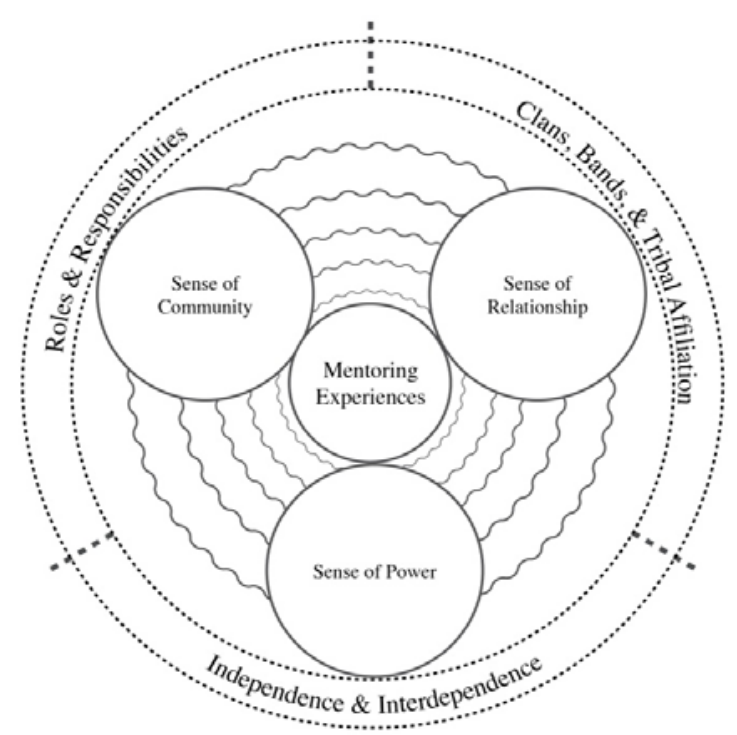

Figure 1: Indigenized Service-Learning Model

The outer circle represents the traditional knowledge embodying relationship, community, and power. Progressing inward, the model demonstrates how the experiences of mentoring radiate to ignite Indigenous knowledge. The process is reciprocal as service learning brings forward Indigenous knowledge and Indigenous knowledge informs the service-learning experience.

\section{Sense of Relationship}

Historical research and cultural memoirs show the various accounts of how this sense of relationship is more than just family lineage normally found in mainstream American culture (Hertzberg, 1971). Cajete (2005) states that, "relationship is the cornerstone of Tribal community" (p. 165). Two examples will be given to show how a sense of relationship among American Indians compares to other ethnic groups. First, prior to contact, Indigenous peoples sophisticatedly navigated their homelands and relationship to others through clan systems and bands (Deloria, 1994). There was an inherit flow of resources back and forth as land was not viewed as possessed by individual tribal nations. This is not to say there was never conflict between groups. Rather, there was constant reliance on each other, both within and beyond individual communities, for survival. This interdependence could be observed through trading, hunting, and even raiding. Specifically through trading and raiding, Indigenous communities increased relations as knowledge was shared and adopted.

Secondly, after European contact, American Indian communities were faced with circumstances such as federally run boarding schools focused on the complete tearing away from their cultural way of life to assimilation, embracing and adopting European values (Child, 1994; Reyhner \& Eder, 2004). Currently, there exist memoirs of American Indians who experienced the stripping of their culture while attending those boarding schools, and in order to survive these students often created bonds between each other despite tribal affiliation. Thus, despite being removed from community influence, the young students rallied together to form alliances that were at times cross tribal. Today, 
American Indians continue to identify themselves through their tribal nations, clans, and bands that existed before European contact and into this modern era. The American Indian mentors knew they were going to be paired with other American Indian high- and middle-school students, but it was unknown as to whether they would share the same tribal background. Thus, the mentors spoke of their approach to the mentor/mentee relationship as taken carefully and slowly with the intent of allowing the mentee(s) and themselves to grow comfortable in the relationship.

Relating to my mentee, I try to find the stories and experiences and then inspirations that he or she has found in their life and-if they don't have any, I mean, I don't know how many people can relate to my story, but I know that there are different stories out there-and you can....anyone can...can really turn any story into a positive thing, but I just try to relate to him or her on that level and I just...I try to keep it friendly all the time. (John, personal communication, March 12, 2009)

Though the mentors recognized that they shared a similar cultural background with their mentee(s) as American Indians, it was not assumed that it would serve as the root of their relationship, as most mentors indicated that their mentee(s) did not come from the same tribal background. Thus, the mentors used the friendship approach, tried to put themselves in their mentee(s) "shoes" and remember what it was like to be in high school. They recognized that they were nervous at first, so they allowed the relationship to grow gradually, with each mentor and mentee learning from one another.

Katie responded in this way when asked about what aided her in the beginning relationship with her mentee:

Knowing that we are from the same ethnic background, not the same tribe but the same ethnic background so in that I mean there are cultural ties like...like humor, the importance of food, eating like stuff like that, that we can relate at a very surface level. (personal communication, April 9, 2009)

Sharing a similar cultural background served to help the mentors recognize the importance of the mentoring relationship while also gaining a greater understanding of the impact they could have on their mentee(s) by relating through their own experiences. Jackie shared,

I guess like I said it was easier because we were both Native American. I guess we came from the same background. If she goes to college, she would be the first of her siblings to go. And that's somewhat similar to mine...me and my family. (personal communication, March 12, 2009)

One particular mentor, Michelle, mentioned how she felt comfortable from the beginning with her mentee(s), in part because they were both American Indian, but what is more important is how she connected her mentoring relationship to being an advocate for more American Indian students to go on to higher education.

I want to go on and further my education and just think of ways to help them, because they are Native American and we do have a...we are the lowest percentage going on to college and finishing high school, so that, it 
just really changed my mind, you know, I was like wow, I really want to help my people go on to college, they just need that, they need someone you know to help them. (Michelle, personal communication, March 13, 2009)

This statement ties into the sense of community category, yet it also belongs in the sense of relationship as well because it describes the impact the relationship had on the mentors in their specific goals and plans after college. Through this statement, Michelle acknowledges how the mentoring experience not only amplified her desire to positively impact her community through her education, but also empowered her to know that she could be that impact for her people.

This knowledge leads into a deeper expression of relationship that the mentors touched upon in their responses. Recognition of how family members could benefit from service-learning experiences surfaced for the mentors through this experience because it was a way for them to understand the importance of the work as well as the knowledge they held about college. In the quote below, Susie shared her thoughts about how this service-learning course has enlightened her personal outlook and how she interacted with a younger sibling.

I mean I think most of all it's helped me think about my little brother because he's 12 years old and everything that we've learned I will definitely be applying to him and saying like I've been telling him like statistics or you know study tips or just a...I know when I was growing up like I really didn't know anything about difference races and ethnicities and how those issues are like buried and I think I kind of grew up in a naïve way you know, when it deals with that, and I want my little brother to like know the stuff that we learn like even yesterday, we learned about token(ism) and multiculturalism and those are some things that I actually didn't know about and so I think that [they're] important for my little brother to know about especially because like he's already thinking about college and he know where he wants to go and he's not going to survive if he doesn't know those kinds of terminology. (personal communication, April 10, 2009)

In addition to Susie, Myles explained how he returned to his hometown to share collegegoing messages to his cousins after serving as a mentor. This ability to relate the mentoring relationship with family members, specifically younger relatives, reveals the power of relationships among American Indian students and their enthusiasm to share that knowledge with their tribal community.

The power of relationships among American Indians can be understood as a ripple effect that begins with the immediate family, on to the extended family and then out to the tribal community. Daisy spoke of how this experience has influenced her career goals, causing her to reconsider following her passion for writing to serve and impact her family and community by becoming a school principal.

I was talking to her (instructor) about being a principal, and going to my high school first because my little brother will go there, and you know, my whole family is still there and will go to my high school if it is still up and running, but...I like my major, and I am really having fun with it, and I am 
always being told to do something you love...but at the same time it is like 'why can't I share what I feel, why can't people from my community, from around the reservation, feel the same way?' So in that sense I would want to...go more into education. (Daisy, personal communication, March 4, 2009)

This statement shows the strength of the mentor's relationships to their family and community through their career choices and how it could take them back to the community. This sense of belonging to a community and returning after college to share the knowledge gained leads right into the next section.

\section{Sense of Community}

Closely linked to the sense of relationship is the sense of community found within Indigenous knowledge. Evidence of this notion is closely related to the roles and responsibilities naturally engrained in American Indian communities. Cajete (1994) states that, "community is the natural context of human life and activity" (p. 167). The relationship of humans to each other is just as important as the roles and responsibilities assigned to each individual because if an individual fails to follow protocol of his or her role, it creates an imbalance in life. To ensure a stable equilibrium, the education and development of the individual was specifically at the hands of the whole community. In American Indian Stories, originally published in 1922, Zitkala-Sa (2003) recollects how each person in her family had a specific skill and related character traits to teach her. She recognized that the skill of beadwork by her grandmother was more than just creating a craft, but teaching her diligence and patience. In No Turning Back, originally published in 1964, Polingaysi Qoyawayma (1992) illustrates how traditional Hopi ways, such as Morning Prayer, created security and appreciation for her whole community. Indigenous knowledge demonstrates how individuals are taught specific roles in society to ensure the livelihood of themselves and their community.

The modern version of the traditional teaching of the importance of community can be found in the view of giving back. This is shown through the communal lifestyle that is taught through values and practices, such as sharing of resources amongst community members and participating in community events and ceremonies. What emerged out the notion of giving back to the community was a sense of community, the view of positively impacting the community through education.

Not just my siblings but I think just this whole experience has got me thinking about what my community is going through and how you know if I could just... because a lot of people talk about going back home and giving something to their community and I think that is something that I could do. (Daisy, personal communication, March 4, 2009)

Interestingly, there were three distinct aspects of this sense of community mentioned by the mentors. The first was the recognition of the impact to the local tribal community located near the university, where some of the mentees resided.

I like working at [that high school] because most of the students [are] like the [local tribal reservation], they don't...I don't think there's that many that 
go on to college, so it's good that we're helping them succeed and... try to go on and further their education. (Ashley, personal communication, March 4, 2009)

The second aspect was the recognition of a need for the mentors to return to their respective communities to be of service to the younger generation. Drawing upon their personal experiences within their respective communities, the mentors were aware of the lack of information and resources in the schools they attended in addition to recognizing the importance of community involvement in a student's motivation and success in school. Thus, the mentors felt that they could take what they learned from the course and from working with their mentee to enhance the college knowledge of their families and tribal communities.

I don't know, it's just, like everything we learned in class...I can apply that to home and this system and you need help from your community, you need help from your teachers, and you need help from programs out there. It just all combines together, so you know, it's just not like the individual himself...they need help from everyone you know; everyone takes part in it. Although, that's the other thing too, just trying to...further [your] education...I want to be one of those people to do something about this, about the problems especially Native Americans going into higher education or college...it just really made me aware that...if a student doesn't go on it's not their fault (Michelle, personal communication, March 13, 2009)

The final aspect is on a broader scale, in that the mentors acknowledged a new purpose and understanding of the value of their college education. The traditional teaching of sharing of resources can help to explain how the mentors recognized the knowledge they held by going on to college, and how this knowledge is lacking in the community. This becomes a source of motivation for the mentors to attain their degree and take their knowledge back to the community to share.

So, for me, of course I want to get a degree, of course I want to take in as much of this information as I can. And then somehow tie that to my community first because there are just so many, so many things that I see when I go home that really makes me sad, that no one can experience what I am experiencing out here. I would first like to do that because I lived there and I see it and it is just how can I make an even bigger change without making the smaller ones first? (Daisy, personal communication, March 4, 2009)

These three dimensions of community, local university, and home community built upon each other as the mentors acknowledged the meaningfulness of their work. This section focused on the knowledge the mentors gained through the mentoring experience and how it could be taken back to the community, and thus through the mentoring experience, learning occurred both ways with the mentor and mentee. Hence, this sense of community is related to the sense of power, the last major piece of knowledge to be discussed. 


\section{Sense of Power}

The Merriam-Webster Dictionary (n.d.) defines "power" as the "possession of control, authority, or influence over others.” This mainstream definition indicates that power lies within a human individual and is exerted to control others within its environment. In the context of Indigenous knowledge, power is "the living energy that inhabits....all of the connections or relations" (Deloria \& Wildcat, 2001, p. 140). In this case, power is not something that any one individual possesses; rather, the energy exists in all. Power is generated by the natural interaction between all, including humans, nature, and animals. This dynamic reemphasizes the importance of maintaining a balance of giving and receiving, and establishes an understanding within Indigenous communities of independence and interdependence.

Indigenous knowledge articulates that humans are not the dominator of the life cycle, but this value does not negate the importance of the individual. Rather, Indigenous knowledge stresses the importance of a cyclical relationship between the individual and collective whole. For this reason, diversity among individuals is valued in American Indian communities because the various skills and points of view teach other members, especially the youth, of proper behavior and communal responsibilities (Cajete, 1994). The development of an individual ensures a balance within a community as the individual possesses knowledge, such as experiential knowledge, that contributes to creating a stable community.

Deloria (1994) reconfirms this belief when he stated that the "tribal man is hardly a personal 'self' in our modern sense...he does not so much live in a tribe; the tribe lives in him” (p. 201). Today's sense of power in tribal communities is still evident as many tribes continue to practice traditional ceremonies that rely heavily on the transmission of knowledge from the elders to the youth. This concept of power contrasts with the mainstream American Dream of individual gain. This does not mean one is preferred over the other, but rather the Indigenous term of power creates empowerment of the individual to be aware of their surroundings and to involve him or herself in positive activities.

This experience has affected me in the sense that I know she looks up to me and that she will take into consideration what I [tell] her and I take into consideration what I think about the topic or language I use, the clothes I wear, the environment that I take her into and also I think that inside, like I try to help her to see the big picture of what is going on and every consequence, every decision has a consequence and hopefully she will see what I'm talking about...like life in general I can guide [her] only so much. I mean I am not here to change her life miraculously, direct her down the path of richness or something. I mean in terms of our relationship, she helps me realize what I need to work on, critique myself in terms of present information or information that I need to freshen up or stuff like that. (Katie, personal communication, April 9, 2009)

Deloria and Wildcat (2001) state that "power is quite literally flowing around and into us; if we are properly attentive, power can be used by us" (p. 140). The mentor 
recognizes the power within the relationship and how it is utilized by both mentee and mentor to influence better choices for improved decision making for each other. In the relationship, the mentor realizes that the knowledge one holds by being a college student can positively impact others, and the power one has to share that knowledge.

It has just made me realize that there are people who do need help in overcoming barriers, that I do have the ability to help them, and it taught me a lot about myself in terms of how far I will go to help somebody get access to information that they don't have, and then my perspective on things has changed just from talking to all the students that I have mentored. They have shown me how to think differently in terms of barriers and what-not. (Stacey, personal communication, March 3, 2009)

Thus, the mentoring experience provided opportunities that helped the mentors to recognize that their actions can impact the community. Traditional teaching views the individual as being both independent and interdependent within the community (Cajete, 1994). The rationale behind this view is that learning always takes place in both directions; just as much as the community influences the individual, the individual also influences the community by his or her actions. Coming to this realization served as motivation and empowerment for the mentors to see their place in the academy as a catalyst for making change within the community.

Oh, and just thinking about my mentees...this small group can be such a much larger pool and I can affect so many other people in difference ways and that's just my inspiration has grown a lot more because of them. (John, personal communication, March 12, 2009)

Ultimately, majority of the mentors noted a greater understanding about themselves that they did not have prior to this mentoring experience. It is an understanding gained through recognizing that the relationship developed between the mentor and mentee was cultivated by the influence of the whole environment. This understanding can serve as an example of Deloria and Wildcat's (2001) concept of Power + Place = Personality. The mentors acknowledge their role goes beyond this experience alone, and they accept it.

I guess just in a way it's kind of made me see that no matter where you go you're kind of in a mentoring mode, you know, because in a mentoring [role], people are looking up to you and you're a symbol for something good and like no matter where you are in the public eye somebody's seeing you and your actions play a big role in how they see you, so just in that probably has made me think about like my actions outside of class and outside of mentoring. (Susie, personal communication, April 10, 2009)

In addition to students recognizing their individual sense of power, it is also noteworthy to acknowledge that the mentors exhibited different levels of power through their future plans. When Jessie was asked if she planned on continuing community involvement, she initially responded by saying, "I was kinda thinking about signing up for this class again, but I don't think so. [nervous laugh] I don't...I don't know.” It was not until after the interview ended that she mentioned that she wanted to be more involved and understood the importance, but she "was just lazy" (personal communication, April 17, 2009). Jessie 
recognized her personal power to enact change, but at that time in her life, she had not made the commitment to act upon it. Ana, shared a different level of reflection. She stated, "looking back upon my experience, you have the community college just like right near your campus but you didn't have the college students coming to your classes and telling you what [college is] about” (personal communication, April 9, 2009). Seeing this course as a driving force, Ana now has plans to return to her community to implement an afterschool program to promote a college-going atmosphere.

This section has focused on the mentors' recognition of the power present in the relationship, and the impact this relationship can have within the larger American Indian community. This sense of relationship between the mentors and mentees was characterized as open and without assumptions, thus allowing the learning to mutually happen through the relationship. The mentors acknowledged the impact their mentees had upon their actions and viewpoint within and beyond their interactions together. John related an experience with his mother to his work with his mentees as a personal catalyst for change after completing his degree:

Through my mentees, I think...I found more inspiration to keep going because while I'm helping these 3 students in their own path, I could be helping so much more...once I have a professional degree and then I can actually give speeches and I can give talks to whoever and they'll look up to me and then...I kind of think about a lot of situations...because my mom...she spoke at a [tribal nation] high school out on the reservation. It's actually where she grew up and where she graduated from. It was her high school and I was there a few years ago when she was the speaker for their graduation and...I was so proud of her and I was kind of thinking to myself, "that could be me someday." (John, personal communication, March 12, 2009)

In hearing and processing our brothers and sisters' experiences, it became clear that the three core areas-sense of relationship, sense of community, and sense of power-were not discreet, mutually exclusive categories, but rather, were related to each other. Within the context of how the mentors interpreted the question being asked of their experience, their responses reflected an overlapping of two or even all three of the knowledge bases. Though these ideas were discussed separately, it is important to visually show how they are related. Figure 2: Reflexive Service-Learning is presented below to help explain this connection among the knowledge bases. Located in the middle of the model is the service-learning experience, as it can be understood to be different for each mentor. Through the mentoring experience a sense of relationship, community, and power were triggered and brought meaning not only to the mentoring experience, but also to how their actions expressed each concept differently. The three knowledges are represented by responsive circles, which indicate an interactive relationship. This model reflects how Deloria and Wildcat (2001) view learning "not through lectures but through experience: customs, habits, and practices” (p. 33). 


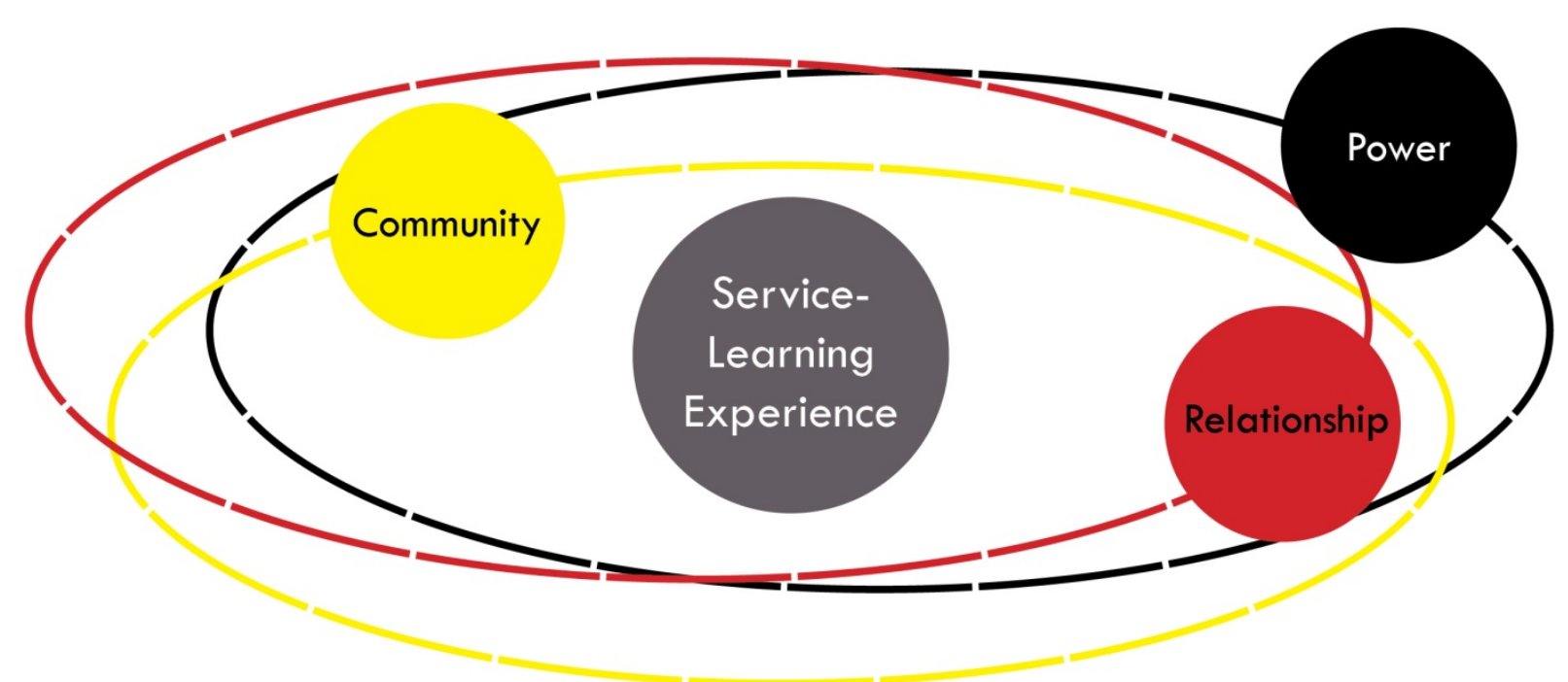

Figure 2: Reflexive Service-Learning Model for American Indian College Students

The responsive circles can be understood to move within and all around each other as the mentoring experience affects how closely the circles align with one another. The concept of Indigenous knowledge organic by nature and this model is not intended to explain all facets of this knowledge base. It is, however, helpful by showing that all the participants had their own interpretation of the three areas: relationship, community, and power. It is also helpful in understanding that a student's interpretation changes as he or she experienced new situations, so a student's placement on the circular track may move closer to an Indigenous Knowledge perspective or vice versa.

\section{Making Meaning of Our Brothers and Sisters' Stories}

This inquiry revealed that our students tapped into their own supply of Indigenous knowledge to relate their mentoring experience to building relationships, being a positive influence on their respective tribal communities, and recognizing that learning is cyclical and how that applies to their role in society, as a whole. The mentors did not mention Indigenous knowledge specifically as an explanation in any of their responses to describe their experiences; rather their descriptions revealed components of Indigenous knowledge from their backgrounds that impacted their mentoring relationship. Such referencing to Indigenous values was not expected as the interview questions were tailored to a larger population of students, not only to the American Indian participants. Thus, to be able to clearly articulate the experiences of American Indians, an Indigenous framework proved to be appropriate to understanding their responses.

Having a sense of belonging to a community and knowing where you come from is a central value in many tribal traditions and teachings. Cajete (1994) identifies community as the environment that teaches Native people the meaning of relationships and responsibility. For the American Indian mentors in this study, the mentoring experience provided ways for them to conceptualize their sense of community to the local Native community near campus, to their specific role in their respective tribal 
communities and the larger society. Furthermore, it was through this service-learning experience that the mentors' concern for community was brought to the forefront, fostered by their sense of power and relationship. These knowledges are of particular importance for future inquiries on American Indian student experience in higher education overall.

Contrary to popular belief that going away to college is where individuals set out on their own, becoming independent, the knowledge presented by the students suggests that they prefer an environment where meaningful relationships and community are present. Our students recognized their ability to have a positive impact on the younger generation, which in turn, empowered them to understand that the meaning of being successful in higher education goes beyond their own sense of accomplishment. Considering the dismal completion rates of American Indian students in higher education, the lived experiences of our students brought to light how the current status of higher education is limited on redirecting this trend. Coupled with the knowledge gained from this inquiry, further analysis is necessary to reframe how institutions understand and develop programming for American Indian college students.

The idea of incorporating Indigenous knowledge into higher education has been supported by current scholars (Brayboy \& Maughan, 2009; Grande, 2004; McNally, 2004). However, there is a gap in the literature that shows how American Indian college students react to the inclusion and use of this knowledge. For example, in his review of incorporating Indigenous knowledge in education settings, Battiste's (2002) most important recommendation was how it could lead to inspire and motivate change at the post-secondary level. Recognition of the positive impact Indigenous knowledge had in our younger brothers and sisters' experiences supports the idea of incorporating Indigenous knowledge in the higher education setting. In addition, it provides a different framework for American Indian students to connect their experiences in college to their cultural backgrounds. There is need for further inquiry on the application of Indigenous knowledge in all realms of higher education, especially its impact upon Native student persistence and success.

When coupling the knowledge we gained from this inquiry with TribalCrit, researchers and practitioners are able to (a) re-evaluate the incongruent nature of mainstream knowledge and Indigenous knowledge and pinpoint inequities that contribute to lack of student success, (b) realize that Indigenous knowledge is a legitimate and powerful tool in the educational system, and (c) show the combination of service learning with mentoring over an extended period can empower American Indian students to recognize their ability to bring about social change within their respective communities. The reflexive service-learning model for American Indian college students incorporates three critical areas of Indigenous knowledge and informs policymakers and practitioners of the multiple dimensions of American Indian college students. The reflexive model demonstrates how experiences, such as service learning, can uncover important cultural underpinnings and how those foundational values can inform future practice. This model advocates for a reciprocal process when working with American Indian students and shows how American Indian students have the essence of culturally relevant power to enact change. It is the hope of this inquiry that our brothers' and sisters' narratives reignites the important and historical role service learning has in terms of social 
movement and transformation element (Harkavy \& Hartley, 2010; Speck \& Hoppe, 2004).

Within our roles as instructors in the program and Indigenous scholars in the university, we recognize our presence could have potentially influenced the mentors' responses. They may have felt more comfortable discussing their experiences with another Native student from the university. They may have also felt that we would understand their responses from an Indigenous perspective. Nonetheless, we were inspired by their responses and the connections they made between their mentorship and service in the local community to their respective tribal communities. It was an honor to work with the mentors and share in their experiences within the program. We thank them for the opportunity to carry forward this work and for the inspiration to bring to light the Indigeneity among Native students in higher education. 